\title{
Some Current Concerns of Neo-Darwinism:Gene Introgression Throughout a Species Border
}

\section{Yuri Ph. Kartavtsev*}

A.V. Zhirmunsky Institute of Marine Biology of the Far Eastern Branch of the Russian Academy of Sciences, Vladivostok 690041; Far Eastern Federal University, Vladivostok 690095, Russia

\begin{abstract}
The author introduces the notion of hybrid and occurrence of hybridization estimates by means of molecular markers. In this editorial evidence on possible impact of gene introgression on species integrity, its evolutionary fate and consistence with main modern paradigm, Neo-Darwinism are considered.
\end{abstract}

Keywords: Gene Introgression; Species Fate; mtdna; ndna; Molecular Evolution

\section{Introduction}

Nowadays, we meet a contradiction in the field of evolutionary biology between the Biological Species Concept (BSC), or in wider sense the Neo-Darwinism, which are accepted by most scientists as basic modern paradigms, and the Phylogenetic Species Concept (PSC). There are also some other novel concerns of the Neo-Darwinism connected with new data in evolutionary genomics, phylogenetics and phylogeography. I will focus on three such sorts of data: (i) gene introgression throughout a species border, (ii) reticulation in a gene tree (or reticulation in wider sense), and (iii) genome mosaicism. While for BSC vs. PSC debates, the contradiction is more apparent than actual $[1,2]$, the attack on the BSC from the three points mentioned above, looks like a serious challenge for it and for the Neo-Darwinism or the Synthetic Theory of Evolution (STE) in general. I will present in brief literature data and my own view that are relevant to these three points under the angle of STE concerns in a few following editorial. No doubt, the STE itself needs development. Strictly speaking, it is even not a theory in a quantitative meaning at all [3-8], and so it should be reformulated in an appropriate mode. There might be other challenging points but I will focus in the current assignment on only the first of three above points, on the gene introgression between species. The other two points will be considered in subsequent issues.

\section{What are Hybrids and Hyridization?}

Let us start with the definition what hybrid is. A hybrid is a mixture, an offspring of cross(es) between genetically different organisms. In other word, hybrids are individuals with a mixed ancestry. In a limiting case, a heterozygote at one or more loci is a hybrid individual. So, the cross $\mathrm{P}_{1}: A_{1} A_{1} B_{2} B_{2} \times A_{2} A_{2} B_{3} B_{3}$ gives the hybrid $\mathrm{F}_{1}=\mathrm{F}_{\mathrm{H}}: A_{1} A_{2} B_{2} B_{3}$. Hybridization is normally a mating process in bisexual organisms by which hybrids occur. This process usually involve small portion of individuals of the species. However, if the number of species that hybridize in nature is big it may be an important evolutionary force. We should recognize the difference between the simple intra-deme crosses and crosses between different lines, demes and species. True hybrids are normally thought to be the offspring of more distant parents. The meaning of distant here is quite conditional, depending on the particular organism and its normal system of breeding. Beyond $\mathrm{F}_{1}$ hybrids, other types of hybrids may develop: $\mathrm{F}_{1} \times \mathrm{F}_{1}=\mathrm{F}_{2}, \mathrm{~F}_{1} \times \mathrm{P}_{1}=$ $F_{b}$ and so on. Hybridization may be either natural or artificial. Here, we will deal mostly with the former. Hybrids need not be exactly intermediate to the parental types, but depending on the complexity of cross can be closer to one of them ([9], Chapter 10). We will look for more details on this point later. It is accepted normally that fitness is lower in hybrids in comparison to parental forms, but this rule does not always hold. Sometimes the reverse is true: hybrid vigor can occur. However, these cases are beyond our theme, and belong largely to the artificial crosses between inbred lines or brood stock kinds/lines. The direct outcome from the definitions given above is that hybrid detection could be properly done with nuclear markers, which are able to detect both parents' impact. Thus, mtDNA markers, which in most cases are maternally inherited via oocyte cytoplasm, could be used but with this reservation. Of course the presence of species A mtDNA (whole mtDNA genome) in species B sometimes is evidence of a past hybridization event. Evidences of hybrid occurrence by usage of solely mtDNA makers; e.g., that may indicate a recombination of an extant gene(s) as reported for instance for the cyprinid fish Gila robusta complex [10] or from Brachymystax lenok into the investigated genome of Siberian taimen, Hucho taimen [11], are only preliminary indicators of possible hybridization. In one of the described cases, mtDNA genes from lenok should be harbored from a female parent because of the presence of two gene sequences from this linage in the taimen genome [11]. However, as evidenced from other sources this direction of cross gives hybrid incompatibility [12], while the backcross gave even heterosis [13]. So, there is certain contradiction in this evidence of hybridization.

The ability and propensity of taxonomically distinct fishes to interbreed and produce viable hybrid offspring are now well established. Schwartz [14,15] compiled nearly four thousand references dealing with the natural and artificial hybridization of fishes. Much earlier Hubbs [16] reviewed the literature on natural hybridization among North American fishes.

Recently a short discussion on this matter was presented in JPGEB [7], so, it is a bit easier to develop these ideas here. Natural hybridization is believed to be more common in fishes than in other groups of vertebrates. Common hybridization applies also to shellfish. One of the most important causes of more frequent hybridization in these groups may be weak chromosomal sex determination in comparison with more advanced organisms, such as mammals. In many fish species sex determination depends upon many factors,

*Corresponding author: Yuri Ph. Kartavtsev, A.V. Zhirmunsky Institute of Marine Biology of the Far Eastern Branch of the Russian Academy of Sciences, Vladivostok 690041; Far Eastern Federal University, Vladivostok 690095, Russia, Tel: +7-4232 311-173; Fax: +7-4232-310900; E-mail: yuri.kartavtsev48@hotmail.com

Received November 27, 2013; Accepted November 30, 2013; Published December 07, 2013

Citation: Kartavtsev YP (2013) Some Current Concerns of Neo-Darwinism:Gene Introgression Throughout a Species Border. J Phylogen Evolution Biol 1: e107. doi:10.4172/2329-9002.1000e107

Copyright: $\odot 2013$ Kartavtsev YP. This is an open-access article distributed under the terms of the Creative Commons Attribution License, which permits unrestricted use, distribution, and reproduction in any medium, provided the original author and source are credited. 
and sex chromosomes may be either absent or their effects negligible [17]. Several other biological peculiarities of fish and shellfish species may also account for this distinction: e.g. external fertilization, weak ethological isolating mechanisms, unequal abundance of the two parental species, competition for limited spawning habitat, and susceptibility to secondary contact between recently evolved forms [18]. These peculiarities are affected to varying levels by local habitat.

Natural and man-induced changes in environmental conditions are often cited as causes of hybridization in fishes. For example, hybridization is relatively common among temperate freshwater fishes in areas where geological and climatic events since the Pleistocene have drastically altered aquatic environments. However, hybridization appears to be rare in marine and tropical fishes that inhabit more stable environments. Man-caused habitat changes in North America and other regions have also been correlated with hybridization between both previously allopatric and naturally sympatric pairs of species [1922]. For salmon, such examples were summarized by Simon, Nobble [23] and Altukhov, Salmenkova [24]. It is estimated that hybridization could influence the fate of around $25 \%$ of plant species and $10 \%$ of animal species, mostly young, recently diverged species [25]. I will mostly focus on animal species that are more easily understandable in the framework of the BSC. Recent publications for them involve conservation aspect [26], recent historic change [27], and frequency of hybrid occurrence in different taxa; e.g., in birds [28] compared with other vertebrates $[29,30]$.

For general discussion, we need to define terms of genes exchange precisely. First, we will refer to gene flow as the process marked by selectively neutral (or nearly neutral) alleles and accept that reproductive isolation between biological species means absence of any gene flow (in the sense that $F_{1}$, and especially $F_{2}$ or $F_{b}$ are infertile and unviable or low in fertility and viability); this is the strict BSC requirement. Second, the hybrid zone is an area where natural hybrids occur between supposed parental forms. Usually, in such an area, a cline arises. Third, cline is a gradual or abrupt allele frequency change in a mode: Species 1 (Deme 1 ) $\rightarrow$ Hybrids $\rightarrow$ Species 2 (Deme 2) and is maintained by a balance between dispersal and selection against hybrids (Modified from [31]).

\section{Methods of Hybrid Detection}

There are at least four methods of hybrid detection [4,9,18]. Most efficient is detection by isozyme and nuclear DNA (nDNA) markers when parents had different fixed alleles $[4,9,18]$. Hybrid detection when nDNA is used in a combination with mtDNA allows for better resolution of a parental cross direction, because of maternal inheritance of mtDNA. An example of such successful use of joint markers was presented recently for turtles of the genus Mauremys [32].

\section{Gene Introgression throughout a Species Border}

\section{Data and general discussion}

Exact scientific solution is not easy to achieve for the above heading because there are no exact tools to define which taxon has reached species status, or which has not. In this connection, exact delimitation of species is a very important challenge for evolutionary genetics and evolutionary biology in general [3-6,33]. It is well known that mtDNA could spread through species barriers and may exist many generations within gene pools of species, whose biological integrity is documented by other molecular markers and by phenotypic traits. Despite many contradictions, these facts are well documented by data from mice [34,35], frogs, fish, mussels, and other organisms [36]. Investigation of mtDNA genotypes, in combination with nuclear DNA markers or isozyme loci, has sometimes demonstrated the ability of mtDNA to introgress from one species to the other species, if the hybrids between these species and their progeny are fertile and in this case make an impact on the nuclear vs. cytoplasmic background. This introgressive hybridization requires successful backcrosses of the ancestral hybrid female with males of the parental species or other taxa. Such introgression is independent of recombination and segregation events, occurring in the nuclear genome, if natural selection, maintaining nuclear-cytoplasmic compatibility, is absent [37,38]. However, evidence of this kind appears increasingly often, indicating operation of subtle selective mechanisms that maintain the interaction of nuclear and, for example, mitochondrial genes [39]. However, a number of cases of mtDNA introgression (see references below) show that possible selection, if it exists at all, is not sufficiently strong to prevent hybridization and introgression. Thus, the instances of finding foreign mtDNA in species' hybrids in nature, as identified by other methods, may be a proof of hybridization of closely related species (taxa), but may not be very influential on the evolutionary fate of the species itself. The interspecies mtDNA transfer has been found in species of invertebrates (Drosophila) and vertebrates (Mus, Apodenus and Rana) $[34,35-43]$. Literature on the topic has already considered with the aim of comparative analysis $[1,35,42,18]$. Based on an analytical approach for the analysis of nuclear-cytoplasmic equilibrium [44,45], an original method has been developed for testing the direction of hybridization and the intensity of introgression [36]. Here, I can only briefly touch upon the issue of mtDNA introgression, to elucidate its relationship with the species status in the BSC.

Asymmetry of the introgression as demonstrated for two species of Hyla frogs is especially obvious on the nuclear-cytoplasmic interaction data, and it is frequent in nature [36]. For many cases that were analyzed, the spread itself through the interspecies borders by mtDNA genes, as well as probably by some mobile elements from the "foreign" genomes, did not necessarily cause species' disintegration. Moreover, in some cases, as it is supposed by the BSC, new mtDNA genes harbored via introgression may take their part in the formation of RIBs (Reproductive Isolating Barriers). Action of RIBs depends upon development of the nuclear-cytoplasmic relations and on other biotic and abiotic events. An example of current contradictive development of RIBs under hybridization, urbanization and climate change representing different pairs of taxa is the Mytilus ex. group edulis complex [46-51]. Nowadays the monitoring of hybridization and introgression is, possibly, one of most important goals of evolutionary and general genetics. This is especially true taking into account available data on claimed numerous examples of reticulate evolution and gene introgression among many marine organisms $[11,52,53]$. Analysis for part of evidences for hybrid occurrence provided for animals [52] shows that in many cases examples do not really represent the interspecies introgression but rather intraspecies introgression, introgression between taxa of an uncertain rank or between such taxa as subspecies/semispecies, which may not be contradictive to the BSC [7]. Data in [11] as was mentioned above are contradictive and at most represent a very rare case of double recombination event that may take place due to artificial crossing or even came from rare natural hybridization in historical time. In the review [52] there is evidence of introgression that indicates the presence of hybrids but not introgression itself. It is well known that the presence of $F_{1}$ hybrids, even confirmed genetically, does not necessarily mean that gene introgression occurred [18]. For some groups of fish hybridization is common [18] but only sporadic introgression occurs [54]. Also, it is quite well known that these events are caused by drastic past climate changes, as evidenced for instance for char $[55,56]$. There is in the review some evidence based on morphological traits [52] but 
this may be only rough information and hardly acceptable as signs of gene introgression $[28,18]$. Very thorough fish species investigation based on mtDNA and nuclear allozyme markers showed that in most cases hybrids are only $F_{1}$, so they suggest no real gene introgression had occurred [56]. However, there are estimates of the opposite kind that demonstrated presence of advanced backcrosses [57,58]. In the first case mtDNA and nuclear microsatellite loci determined presence of backcrosses in high frequency (44.9\%) have been obtained [57]. In the second case also a combination of markers was used, and indicated gene flow among four cichlid species in Lake Tanganyika [58]. However in most cases, we do not know exact figures on the introgression level or gene flow. Cases of introgression that were presented for sea weeds [53] are currently rare and generally correspond with facts that are known for terrestrial plants; i.e., they support weakness of reproductive barriers in many plant "species". Also, this evidence [53], as well as that presented for the Siberian taimen [11], is based on the rare recombination event in mtDNA; thus, conclusions on gene introgression by hybridization from here may be only provisional suppositions. However, in the latter case authors advocated that artificial cross may stimulate and increase the recombination rate [11]. Anyway, the real mechanism of recombination remains unknown. Certainly, hybridization is the main candidate source for introgressed DNA. However, gene introgression may be also caused for instance by a bacterial or viral recombinant vectors harboring those genes with the subsequent recombination event within host fish. Also, no indications are presented in the papers cited, which kind of hybrids were presented, $\mathrm{F}_{2}, \mathrm{~F}_{3}$, etc. Even worse, in one of the two cases [11] the recombinant specimen that obtained in the research is not the authors' sequence but have been retrieved from GenBank, part of which may have simply result from laboratory errors.

In conclusion, it seems that claims on a crush of the modern BSC paradigm [52,59] due to wide-scale gene introgression are too premature, even keeping in mind the long history of many hybrid zones $[60,61]$. Contrary to that, evidence that summarized here and in earlier reviews $[3,5-6]$ show that molecular genetic data are concordant with the BSC and Neo-Darwinism/STE in general. It is clear that introgression exists, although even in a wide zone of Mytilus spp., for example, it may be quite restricted [48] or be asymmetric (see above and $[50,62,63])$, so holding intact at least the "source" taxa. Anyway, we should be very careful in hybrid detection on mtDANA markers data only. Detection of hybrid by solely mtDNA evidence may cause even erroneous results. E.g., mussels have double uniparental mtDNA inheritance. MtDNA from paternal and maternal lines within same species may have nucleotide diversity of about $8.3 \%$ at 16s rRNA [64]. In an investigation of the interspecies divergence by mtDNA markers, make without discrimination of two sexes, many substitutions and indels may be easily found and promising speculations on evolutionary fate or hidden taxa made. If we accept that the sexually reproducing species in marine and terrestrial realms are introgressed, then we should recognize that the orthodox biological species concept, as we define it earlier in the Introduction in terms of gene flow absence among species, is inadequate in a sense that many taxonomic species are not biological species yet. However, sooner or later they become to, which conclusion supported by genetic distance increase with taxa rank and minimal diversity at intraspecies level [5-7].

More details on the theoretic and empiric investigation on hybrid occurrence, hybridization and gene introgression are available elsewhere $[25,31,60,65]$. I am aware that many things on hybridization are obscure and sophisticated, so the final solution may not be found soon. Anyway, in my view, despite consistency or inconsistency of current biological concepts, species are able to maintain their integrity and authenticity, at least in a testable retrospective or in a provisional perspective.

\section{Acknowledgments}

I am very thankful to Drs. B. Ward, M. Singh, M. Johnson, H. Suzuki, and A Oleynik for proofreading of the manuscript. This work was supported in part by Far Eastern Branch of Russian Academy of Science grants: \# 12-I-OBN-07, 12-IICO-06-017, and RFBR 14-04-00758.

\section{References}

1. Avise JC, Wollenberg K (1997) Phylogenetics and Origin of Species. Proc. Natl Acad. Sci. USA 94: 7748 - 7755.

2. Avise JC (2000) Phylogeography. The history and formation of species. Harvard University Press Cambridge $447 \mathrm{p}$.

3. Kartavtsev Y Ph (2009a) Analysis of sequence diversity at mitochondrial genes on different taxonomic levels. Applicability of DNA based distance data in genetics of speciation and phylogenetics Chapter 1. Nova Science Publishers Inc., New York, USA, 1-50.

4. Kartavtsev Y Ph (2009b) Molecular Evolution and Population Genetics. (Edn 2) Far Eastern State Univ. Publ, Vladivostok, Russia, 280 p.

5. Kartavtsev $\mathrm{Y} P \mathrm{Ph}$ (2011a) Sequence divergence at mitochondrial genes in animals. Applicability of DNA data in genetics of speciation, phylogenetics and molecular ecology. Mar Genomics 49: 71-81.

6. Kartavtsev $\mathrm{Y} P h(2011 b)$ Sequence divergence at Co-1 and Cyt-b mtDNA on different taxonomic levels and genetics of speciation in animals. Mitochondrial DNA 2: 55-65.

7. Kartavtsev Y Ph (2013a) Sequence Diversity at Cyt-b and Co-1 mtDNA Genes in Animal Taxa Proved Neo-Darwinism. J. Phylogen Evolution Biol 1: 1-5.

8. Zhuravlev YN, Avetisov VA (2006) The definition of life in the context of its origin. Biogeosciences 3: 281-291.

9. Kartavtsev Y Ph (2013b) Molecular evolution and population genetics. A course for marine biology students LAP LAMBERT Academic Publishing 250 p.

10. GerberAS, Tibbets CA, Dowling TE (2001) The role of introgressive hybridization in the evolution of the Gila robusta complex (Teleostei: Cyprinidae). Evolution 55: 2028-2039

11. Balakirev ES, Romanov NS, Mikheev PB, Ayala FJ (2013) Mitochondrial DNA variation and introgression in Siberian taimen Hucho taimen. PLoS One 8 e71147.

12. Wang J, Kuang YY, Tong GX, Yin JH (2011) Genetics analysis on incompatibility of intergeneric hybridizations between Hucho taimen ( $\delta$ ) and Brachymystax lenok $(9)$ by using 30 polymorphic SSR markers. J Fish Sci China 3: 547-555.

13. Xu LX, Kuang YY, Tong GX, Ding L, Liu B, et al. (2011) An analysis on genetic constitution of Hucho taimen, Brachymystax lenok and hybrids (Hucho taimen [female] x Brachymystax lenok [male]) by SRAP markers. Acta Agric Univ Jiangxiensis 33: 1187-1194.

14. Schwartz FJ (1972) World literature on to fish hybrids, with an analysis by family, species and hybrid. Publications of the Gulf Coast Res Lab Amuseum 3: $328 \mathrm{p}$.

15. Schwartz FJ (1981) World literature on to fish hybrids, with an analysis by family, species and hybrid; Supplement 1. U.S. Dep. Commerce: 507 p.

16. Hubbs CL (1955) Hybridization between fish species in nature. Syst Zoology 4: 1-20.

17. Kirpichnikov VS (1979) Genetic basis for fish breeding. Leningrad Science Publ: $392 \mathrm{p}$.

18. Campton DE (1987) Natural hybridization and introgression in fishes. Method of detection and genetic interpretation. In: Population Genetics \& Fishery Management, Eds. N. Ryman and F. Utter, pp 161-192.

19. Hubbs C, Kuehne RA, Ball JC (1953) The fishes of upper Guadelupe River,Texas . Texas Journal of Science 5: 216-244.

20. Nelson JS (1966) Hybridization between two cyprinid fishes, Hybopes plumbea and Rhinichthys cataractae, in Alberta. Can J Zool 44: 63-968.

21. Nelson JS (1973) Occurrence of hybrids between longnose sucker (Catastomus catastomus) and white sucker (C. commersoni) in upper Canananaskis Resorvoir, Alberta. J Fish Res Board Can 30: 557-560. 
Citation: Kartavtsev YP (2013) Some Current Concerns of Neo-Darwinism:Gene Introgression Throughout a Species Border. J Phylogen Evolution Biol 1: e107. doi:10.4172/2329-9002.1000e107

22. Stevenson MM, Buchanon TM (1973) An analysis of hybridization between the cyprinodont fishes, Cyprinodon variegates and C. elegans. Copeia: 682-692.

23. Simon RC, Noble RE (1968) Hybridization in Oncorhynchus (Salmonidae). I. Viability and inheritance in artificial crosses of chum and pink salmon. Transactions of Amer Fisheries Soc 97: 109-118.

24. Altukhov YuP, Salmenkova EA, Omeltchenko VT (1997) Population genetics of salmon species. Moscow Nauka Publ: $288 \mathrm{p}$

25. Arnold ML (1997) Natural hybridization and evolution. Oxford University Press UK, $215 \mathrm{p}$.

26. Genovart M (2008) Natural hybridization and conservation. Biodivers Conserv 18: $1435-1439$.

27. Seehausen O (2004) Hybridization and adaptive radiation. Trends Ecol Evol 19: 198-207.

28. Grant PR, Grant RB (1992) Hybridization of bird species. Science 256: 193197.

29. Prager EM, Wilson AC (1975) Slow evolutionary loss of the potential for interspecific hybridization in birds: a manifestation of slow regulatory evolution. Proc Natl Acad Sci USA 72: 200-204.

30. Fitzpatrick BM (2004) Rates of evolution of hybrid unviability in birds and mammals. Evolution Int J Org Evolution 58: 1865-1870.

31. Barton NH, Hewitt GM (1985) Analysis of hybrid zones. Ann Rev Ecol Syst 16: 113-148.

32. Fong JJ, Chen TH (2010) DNA evidence for the hybridization of wild turtles in Taiwan: possible genetic pollution from trade animals. Conserv Genet 11: 2061-2066.

33. Brower AVZ (1999) Delimitation of phylogenetic species with DNA sequences: A critique of Davis and Nixon's population aggregation analysis. Systematic Biology 48: 199-213.

34. Yonekawa H, Moriwaki K, Gotoh O, Hayashi JI, Watanabe J, et al. (1981) Evolutionary relationships among five subspecies of Mus musculus based on restriction enzyme cleavage patterns of mitochondrial DNA. Genetics 98: 801816.

35. Yonekawa H, Tsuda K, Tsuchia K, et al. (2000) Genetic diversity, geographic distribution and evolutionary relationships of Mus musculus subspecies based on polymorphism of mitochondrial DNA. In: Problems of Evolution, pp: 90-108.

36. Avise JC (2001) Cytonuclear genetic signatures of hybridization phenomena: Rationale utility and empirical examples from fishes and other aquatic animals. Review in Fish Biol Fisheries 10: 253-263.

37. Takahata N, Slatkin M (1984) Mitochondrial gene flow. Proc Nat Acad Sci: 81 1764-1767.

38. Nei M (1987) Molecular evolutionary genetics. Columbia Univ Press. Newyork USA, $512 p$

39. Powell JR (1983) Interspecific cytoplasmic gene flow in the absence of nuclear gene flow: Evidence from Drosophila. Proc Nat Acad Sci USA 80: 492-495.

40. S D Ferris, R D Sage, C M Huang, J T Nielsen, U Ritte, et al. (1983) Flow of mitochondrial DNA across a species boundary. Proc National Acad Sci 80 2290-2294.

41. Spolsky C, Uzzell T (1984) Natural interspecies transfer of mitochondrial DNA in amphibians. Proc Nat Acad Sci 81: 5802-5805.

42. Suzuki H, Filippucci MG, Chelomina GN, Sato JJ, Serizawa K, et al. (2008) A biogeographic view of Apodemus in Asia and Europe inferred from nuclear and mitochondrial gene sequences. Bioch Genetics 46: 329-346.

43. Suzuki H, Yasuda SP, Sakaizumi M, Wakana S, Motokawa M, et al. (2004) Differential Geographic Patterns of Mitochondrial DNA Variation in Two Sympatric Species of Japanese Wood Mice, Apodemus speciosus and A. argenteus. Genes Gene Syst 79: $165-176$

44. Clark AG (1984) Natural selection with nuclear and cytoplasmic transmission: I. A deterministic model. Genetics 107: 679-701.

45. Asmussen MA, Arnold J, Avise JS (1987) Definition and properties of disequilibrium statistics for associations between nuclear and cytoplasmic genotypes. Genetics 115: 755-768.

46. Skibinski DOF, Beardmore JA, Cross TF (1983) Aspects of the population genetics of Mytilus (Mytilidae: Mollusca) in the British Isles. Biol J Linn Soc 19: $173-183$
47. Gardner JPH, Skibinski DOF (1988) Historical and size-dependent genetic variation in hybrid mussel populations. Heredity 61: 93-105.

48. Rawson PD, Secor CL, Hilbish TJ (1996) The effect of natural hybridization on the regulation of doubly uniparental MtDNA inheritance in blue mussels (Mytilus spp.). Genetics 144: 241-248.

49. Skurikhina LA, Kartavtsev Yu F, Chichvarkhin A Yu, Pan'kova MV (2001) Study of two species of mussels, Mytilus trossulus and Mytilus galloprovincialis (Bivalvia, Mytilidae), and their hybrids in Peter the Great Bay of the Sea of Japan with the use of PCR markers. Genetika 37: 1717-1720.

50. Kartavtsev $Y$ Ph, Chichvarkhin AY, Kijima A, Hanzawa Naoto, Park IS, et al. (2005) Allozyme and morphometric analysis of two common mussel species of Mytilus genus (Mollusca, Mytilidae) in Korea, Japan and Russia waters. Korean J Genetics 27: 289-306.

51. Vainolla R, Strelkov P (2011) Mytilus trossulus in Northern Europe. Mar Bio 158: $815-833$.

52. Arnold ML, Fogarty ND (2009) Reticulate evolution and marine organisms: the final frontier. Int J Mol Sci 10: 3836-3860.

53. Balakirev ES, Krupnova TN, Ayala FJ (2012) DNA variation in the phenotypicallydiverse brow alga Sacharina japonica. BMC Plant Biology 12: 108-126.

54. Avise JC, Saunders NC (1984) Hybridization and introgression among species of sunfish (Lepomis): Analysis by mitochondrial DNA and allozyme markers. Genetics 108: 237-250.

55. Glemet H, Blier P, Bernatchez L (1998) Geographical extent of Arctic Char (Salvelinus alpinus) mtDNA introgression in brook char populations ( $\mathrm{S}$. fontinalis) from Eastern Quebec Canada. Mol Ecol 7: 1655-1662.

56. Oleinik AG, Skurikhina LA (2010) Mitochondrial DNA diversity and relationships of endemic charrs of the genus Salvelinus from lake Kronotskoye (Kamchatka Penisula). Hydrobiologia 650: 145-159.

57. Roberts DG, Gray CA, West DJ (2010) Marine genetic swamping: hybrids replace an obligately estuarine fish. Mol Ecol 19: 508-520.

58. Nevado B, Fazalova V, Backeljau T, Hanssens M, Verheyen E (2011) Repeated unidirectional introgression of nuclear and mitochondrial DNA between four congeneric Tanganyikan cichlids. Mol Biol Evol 28: 2253-2267.

59. Arnold ML, Emms SK (1998) Paradigm lost: natural hybridization and evolutionary innovation. In: Endless forms: species and speciation. Oxford Univ Press, Newyork, USA, pp. 379-389.

60. Hewitt GM (2011) Quaternary phylogeography: the roots of hybrid zones. Genetica 139: 617-638.

61. Oleinik AG (2013) Molecular evolution of char of Salvelinus genus: Phylogenetic and phylogeographic aspects. Zhirmunsky Institute of Marine Biology: $47 \mathrm{p}$.

62. Heath DA, Rawson PD, Hilbish TJ (1995) PCR-based nuclear markers identify alien blue mussel (Mytilus spp.) genotypes on the west coast of Canada. Can J Fish Aquat Sci 52: 2621-2627.

63. Rawson PD, Argawal V, Hilbish TJ (1999) Hybridization between the blue mussels Mytilus galloprovincialis and $M$. trossulus along the pacific coast of North America: Evidence for limited introgression. Marine Biol 134: 201 - 211.

64. Rawson PD, Hilbish TJ (1995) Evolutionary relationships among among the male and female mitochondrial DNA lineages in the Mytilus edulis species complex. Mol Biol Evol 12: 893-901.

65. Smith GR (1992) Introgression in Fishes: Significance for Paleontology, Cladistics, and Evolutionary Rates. Syst Biol 41: 41-57. 